Laser and Particle Beams (1985), vol. 3, part 3, pp. 317-318

Printed in Northern Ireland

\title{
Conference announcements
}

7 th International Workshop on

\section{LASER INTERACTION AND RELATED PLASMA PHENOMENA}

28 October-1 November, 1985

Naval Postgraduate School Monterey, California

Presentations and discussions of selected key topics regarding powerful lasers and their interactions with plasmas up to and including extreme intensities and short (X-ray) wavelengths will be continued in the 7 th meeting of this traditional series. The format will remain the same as in the previous workshops and will include latest research results; extensive reviews of key areas, discussion of controversial views, plus speculation about future directions.

The committee for the 7th Workshop includes: Prof. Heinrich Hora and Prof. George H. Miley, co-directors, Prof. Fred Schwirzke, local organizer. The conference fee is $\$ 350$ while a limited number of scholarships are available. To obtain future announcements, please contact: Mrs. Chris Stalker, 214 Nucl. Engin., 103 South Goodwin Ave, Urbana, Ill. 61801, USA.

17th European Conference on

\section{LASER INTERACTION WITH MATTER (ECLIM)}

18-22 November, 1985

Rome, Italy

The 17th European Conference on Laser Interaction with Matter (17th ECLIM) will be devoted to:

Experimental and Theoretical Studies of Laser-Plasma Interactions

Hydrodynamics

Transport

Laser-Driven Implosions

Numerical Simulation

Diagnostics

Reactor Concepts and Drivers for Inertial Confinement Fusion

Physics of High Density Matter

Laser Plasma X-ray Spectroscopy

$\mathrm{X}$-ray Lasers

Organizer: Dr. Angelo Caruso, ENEA Energy Research Center, PO Box 65, 00044 Frascati, Italy.

6th International Conference on

HIGH POWER PARTICLE BEAMS

9-12 June, 1986

Kobe, Japan

This conference serves as the principal forum for the exchange of information and discussion in the technology of high power particle beams and their applications. 
The program will include major review papers followed by invited talks. These presentations will be supplemented by contributed papers. Subject areas of interest include, but are not limited to:

High Power Particle Beam Technology

Diagnostics of High Power Particle Beams

Beam Fusion Applications

New Concept-High Power Accelerators

Applications for EM Waves

Industrial Applications

Imploding Plasma Loads

Conference Chairman: Prof. C. Yamanaka, ILE, Osaka University, Suita, Osaka 565, Japan.

4th International Conference on

EMERGING NUCLEAR ENERGY SYSTEMS (ICENES 4)

30 June-4 July 1986

Madrid, Spain

Sponsors: Spanish Nuclear Society; USSR Academy of Sciences; American Nuclear Society; Canadian Nuclear Society; European Nuclear Society; Atomic Energy Society of Japan; International Atomic Energy Agency and Junta de Energía Nuclear.

Main Topics: Reactor cavity analysis; Hybrid and symbiotic fission-fusion reactors; Accelerator breeding; Small fusion reactors $(<100 \mathrm{MW})$; New breeder reactor concepts; Inertial Confinement Fusion; Catalyzed fusion; Polarized fuel fusion; Impact and explosive driven fusion; Non-conventional fusion systems; New concepts in nuclear energy; Nuclear energy prospects; Role and implications of emerging nuclear energy systems; The impact of new nuclear technologies.

Enquiries: Professor Guillermo Velarde, Director Dept. of Nuclear Energy. E.T.S. Ingenieros Industriales. Universidad Politécnica de Madrid. P Castellana ${ }^{\circ}{ }^{\circ}$ 80. 28046 Madrid. SPAIN. 